\title{
INTEGRATED LOW EMISSION CLEANUP SYSTEM FOR DIRECT COAL-FUELED IURBINES (ELECTROSTATIC AGGLOMERATION)
}

DOE CONTRACT NO. DE-AC21-88 MC-24258

PROJECT QUARTERLY REPORT

FEBRIJARY 1992

FOR THE PERIOD OF $9 / 01 / 91-12 / 31 / 91$

\author{
Prepared BY \\ J. M. QUIMBY \\ RESEARCH-COTTRELI ENVIRONMENTAL SERVICES AND TECHNOLOGIES \\ P.O. BOX 1500 \\ SOMERVILLE， NEW JERSEY
}

\author{
PREPARED FOR THE \\ MORGANTOWN ENERGY TECHNOLOGY CENTER \\ U.S. DEPARTMENT OF ENERGY \\ P.O. BOX 8080 \\ MORGANIOWN, WEST VIRGINIA 26507-0880 \\ DOE CONTRACT SPECIALIST: R. DIANE MANILIA \\ DOE PROJECT MANAGER: CHARLES ZEH
}

\section{DISCLAIMER}

This report was prepared as an account of work sponsored by an agency of the United States Government. Neither the United States Gnvernmemt nor any agency thereof, nor any of their employees, makes any warranty, express or implied, or assumes any legal liability or resporisibility for the acouracy, completeness, or usefulness of any information, apparatus, product, or process disslosed, or represents that its use would not infringe privately owned rights. Refer. ence herein to any specific commercial product, prosess, or service by trade name, trademark, manufacturer, or otherwise does not necessarily constitule a irnply its endorsement, recommendation, or favoring by the United States Government or any agency thereof. The views and opinions of authors ipressed herein do not necessarily state or reflect those of the United States Government or any agency thereoi.

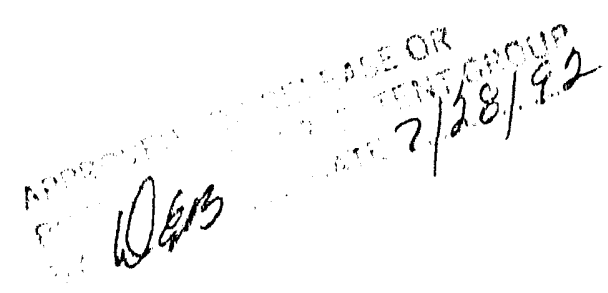

MASTER 


\section{1. objective}

The objective of this contract is to investigate the removal of so $_{x}$ and particulate matter from direct coal-fired combustion gas streams at high temperature and high pressure conditions. This investigation will be accomplished through a bench-scale testing and evaluation program employing sorbent mixed with a coal-water slurry for $\mathrm{SO}_{\mathrm{x}}$ removal, and an innovative particulate control concept. The particulate control device utilizes electrostatic agglomeration followed by a high efficiency mechanical collector (cyclone.)

The process goal is to achieve particulate collection efficiency better than that required by the 1979 new source performance standards. An additional goal is to demonstrate $70 \%$ $\mathrm{SO}_{x}$ removal efficiency.

\section{Technical Approach}

This research project is now in the second of a 3 phase (phase II) project. Phase II is to fabricate the combustor and particulate control devices and install the system at a test facility located at Research-Cottrell's, KVB Western Laboratory, Santa Ana, CA. There are three functional categories, or tasks which are to be completed in sequence. These tasks are itemized as follows:

1. Design, procurement, and installation.

2. Shakedown and startup.

3. Reporting.

CES (R-C, EST) is the Project Manager of the team effort by CES and KVB. KVB (R-C, EST - Western Laboratory) is the sub-contractor to CES for the design and construction of the combustor test facility. KVB will also operate the combustor and gas clean up system to be located at the santa Ana laboratory. CES (R-C, EST) is responsible for the overall testing and evaluation effort including the design and construction of the electrostatic agglomerator and high efficiency cyclone. 


\section{Results/Accomplishments}

Phase I of this contract has been completed. A topical report covering the Phase I effort has been submitted to DOE in March.

\section{PARTICULATE CONTROL CONCEPT}

The DCF'T gas turbine operates at, much higher temperatures than pressurized fluidized bed combustors. At these temperature levels the particulate is likely to contain liquidus species such as sodium sulfate and the potentia! for stickiness should not be underestimated. In view of this likely tendency, a particle control. concept that utilizes a "flow-through" collection concept will offer an advantage that may not be available on barrier filters. Barrier filtration methods may be more prone to plugging at DCFT conditions when compared with flow-through devices such as cyclones.

However, cyclones are known to be deficient in the collection of particulate below 5 microns. Any concept that can help the growth of fine particulate into sizes larger than 10 microns should be promising.

One of the concerns relating to particulate charging is the effect of thermal ionization. The problem associated with thermal ionization is the potential for excessive current flow caused by the presence of an excessive number of thermally generated ions in the combustion gases. In the extreme case even a small voltage applied to a heavily ionized gas would cause runaway currents. cooperman's(1) calculations however, indicate that excessive current should not be encountered up to $1500^{\circ} \mathrm{F}$. Thus, a process limitation because of thermal ionization is not expected.

To test the process where thermal ionization may represent a significant service of ions the electrostatic agglomerator will be first tested during shakedown and startup using stainless steel components. These stainless steel components will provide information on the characteristics of the Electrostatic Agglomerator concept while avoiding sticky particles and thermally 
generated ions. Thus comparison to an electrostatic precipitator, in terms of current voltage characteristics in particle charging can be more readily determined.

once the metal internals verify that the electrostatic agglomerator concept is valid the temperature of the system can be raised to approximately $2100^{\circ} \mathrm{F}$ using high-voltage components fabricated of Hastelloy alloy. The stainless steel internals of the agglomerator that serve as guide plates, baffles, and tube sheets for the high-voltage components will be replaced with ceramic duplicate components.

A complete set of high voltage ceramic internals will replace the Hasteiloy metal internals for temperatures above approximately $2100^{\circ} \mathrm{F}$.

If, however, thermal ionization does occur, there are ways to deal with it depending on the extent of the problem. In the extreme case, where an independent electric field cannot be applied without provoking runaway currents, conditions actually exist which favor self operation of the concept: In the charging section ample thermal ions would be available to charge the particles, and in the agglomerating section, with appropriate electrode spacings, the thermal ion space charge could be adequate to drive the charged particles to the electrodes for contact agglomeration. Thus, even in the extreme case the ESA concept may be valid, although operation would be different from normal.

In the more likely case of little or moderate thermal ionization we have proposed the use of pulse energization to control the current flow. Pulse energization means the application of short-duration fast-rising, high-voltage pulses to a DC base voltage. This provides more degrees of freedom in controlling current production at a given base voltage than in normal DC operation. For example, the DC base voltage can be set below corona starting voltage. Corona starting voltage can be obtained by superimposing a pulsed DC voltage over the base while also controlling parameters of pulse repetition rate, pulse voltage, pulse rise time and duration. Particulate charging and migration, 
and the resultant inter particulate contact are enhanced by the longer residence time of particulates in the agglomerator. A high efficiency cyclone follows the electrostatic agglomerator. The collection efficiency of advanced cyclone has to address the requirements of a 20 ppm outlet so that both turbine requirements and New Source Performance standards could be simultaneously met.

The commercial ESA design for a 200 MW DCFI plant has an interelectrode clearance of 3 inches, and the plate height is 8 feet. A gas velocity of 25 feet per second was chosen in the design of commercial size agglomerator. The fabricability of ceramic internal parts was the main consideration. A vessel diameter of sixteen feet was considered to be the maximum practical size that could be used because of the 8-9 foot limitation on ceramic structural beams. Though presently limited to about $8^{\prime}$ due to fabrication considerations, considerations of moment stress that could be tolerated by ceramics limit structural members to this maximum length. Two $9^{\prime}$ ceramic members could be telescoped to provide the $16^{\prime}$ span and hence the sixteen foot diameter limit on pressure vessels for this application. Once the cross section of ESA is defined, then the length depends on residence time. A length of 30 feet would result in a residence time of 1.2 seconds for a $25 \mathrm{ft} /$ second velocity.

A pulsed energization system using nanosecond risetimes will. energize each section. There will be four electrodes serviced by pulsed power for the 1.2 second residence time operation, and only two for operation with 0.6 seconds residence time. Reliable pulsed power supplies are now available in the industry and the design by Ion Physics corporation will be utilized for these tests.

\section{COMBUSTOR DESIGNS FOR TEST FACILITY}

A CWS combustor with a thermal input of $150,000-300,000$ Btu/hr was initially proposed by AVCO Research Laboratories for simulating gas turbine combustor conditions at the ESA inlet. However, it was later realized that such a small CWS combustor 
would be difficult to operate reliably due to the large heat losses and difficulties associated with atomizing CWS at flow rates below $20 \mathrm{lb} / \mathrm{hr}$. Another very important consideration was the heatup time requirements of the ESA. At the low thermal ratings, the time required to bring the ESA up to the operating temperatures was estimated to be more than 10 hours. In order to alleviate these concerns, the combustor rating was increased to $300,000-1 \times 10^{6}$ Btu/hr. The AVCo subcontract for combustor fabrication and test facility fabrication was changed over to the R-C, KVB Laboratory facility. A report on the combustor design specifications was issued to DOE under separate cover in July 1990. An overall schematic of the design is attached as Figure 1. The reactor specifications are as follows:

a) operating temperature range $1600^{\circ} \mathrm{F}-2500^{\circ} \mathrm{F}$

b) operating pressure: 10-15 atmospheres

c) mass flow: $0.15-0.3 \mathrm{lbs} / \mathrm{s}$ (gas)

d) fuels: CWS or natural gas

A summary of calculated gas temperature data for various loads and excess air levels are shown in Figure 2. The temperatures shown are the gas temperatures at the transition between the 5 " and 2" section. These calculations show that the desired range of temperature $\left(2500^{\circ} \mathrm{F}-1600^{\circ} \mathrm{F}\right)$ can be achieved by varying load between $100 \%$ and $50 \%$ and excess air between $5 \%$ and $100 \%$.

The reactor is designed to provide a suitable residence time to complete combustion of large slurry droplets. over the range of temperature operating conditions the residence time ranges between $0.4 \mathrm{~s}$ and 1.0s. Burnout times for a 200 microns bituminous coal char range from 100 to $200 \mathrm{~ms}$ at temperatures between $3000 \% \mathrm{~F}$ and $2200^{\circ} \mathrm{F}$ under 15 atm pressure and an average $\mathrm{O}_{2}$ concentration of 58 .

The burner design and expected flow pattern is shown in Figure 3. The burner uses swirling flow to stabilize the flame and a curved quarl to delay impingement on the furnace wall. The burner can be fired on natural gas, coal/water slurry or if required, a combination of the two fuels. 


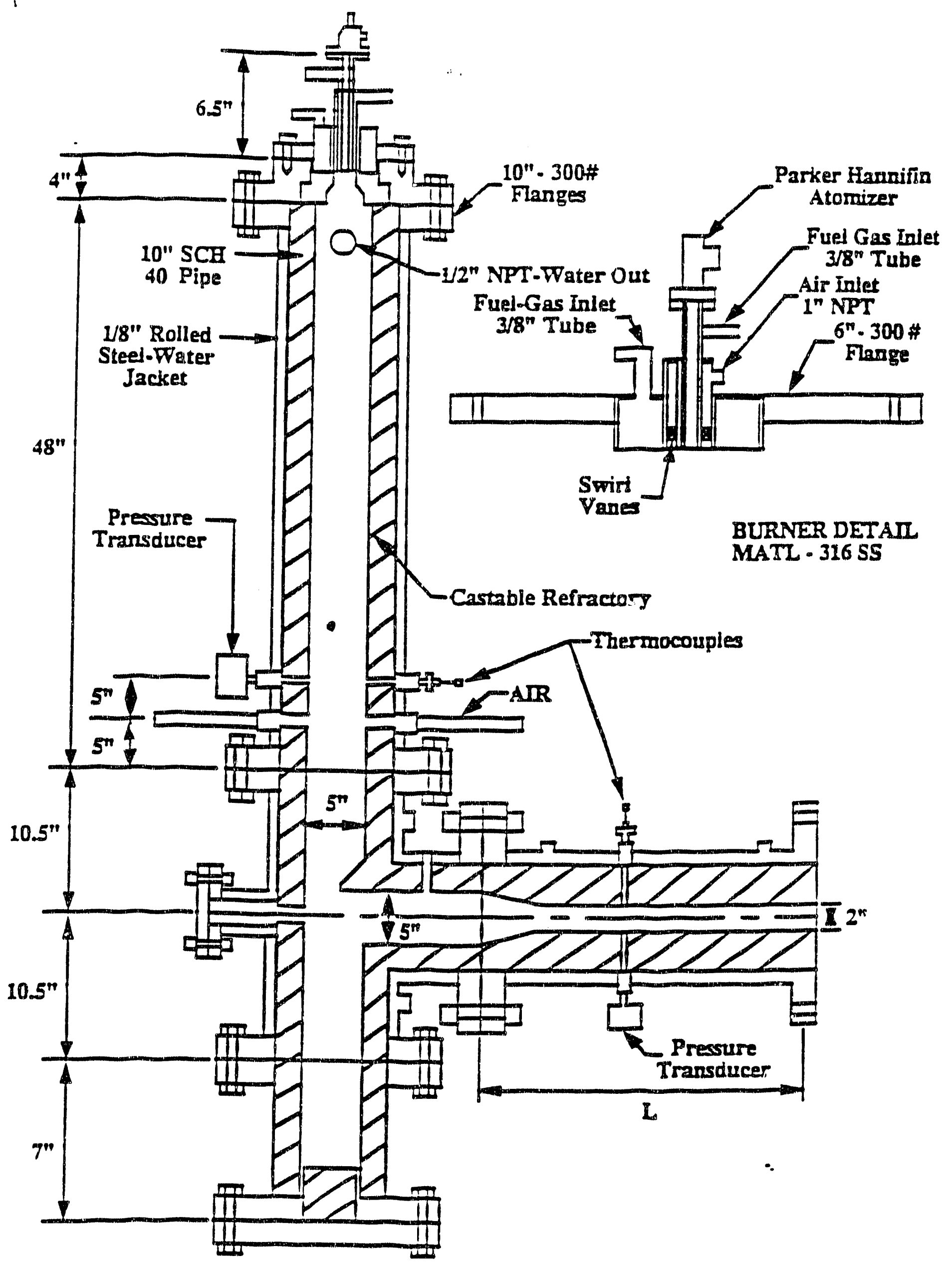

sre 1. DOE - HITHP Combustor Math - Carbon Steel 


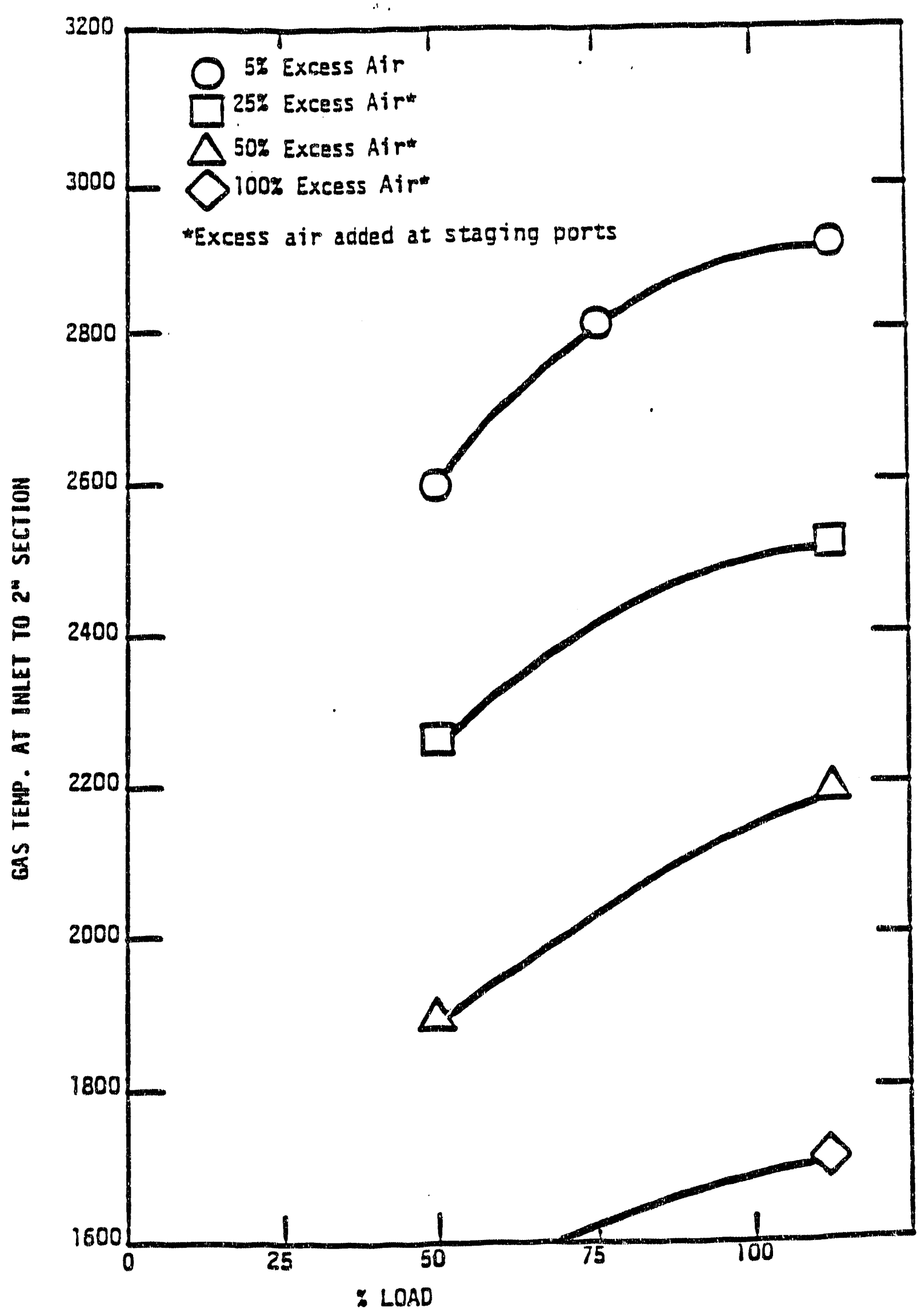

Figure 2. Calculated reactor exit gas temperatures. 


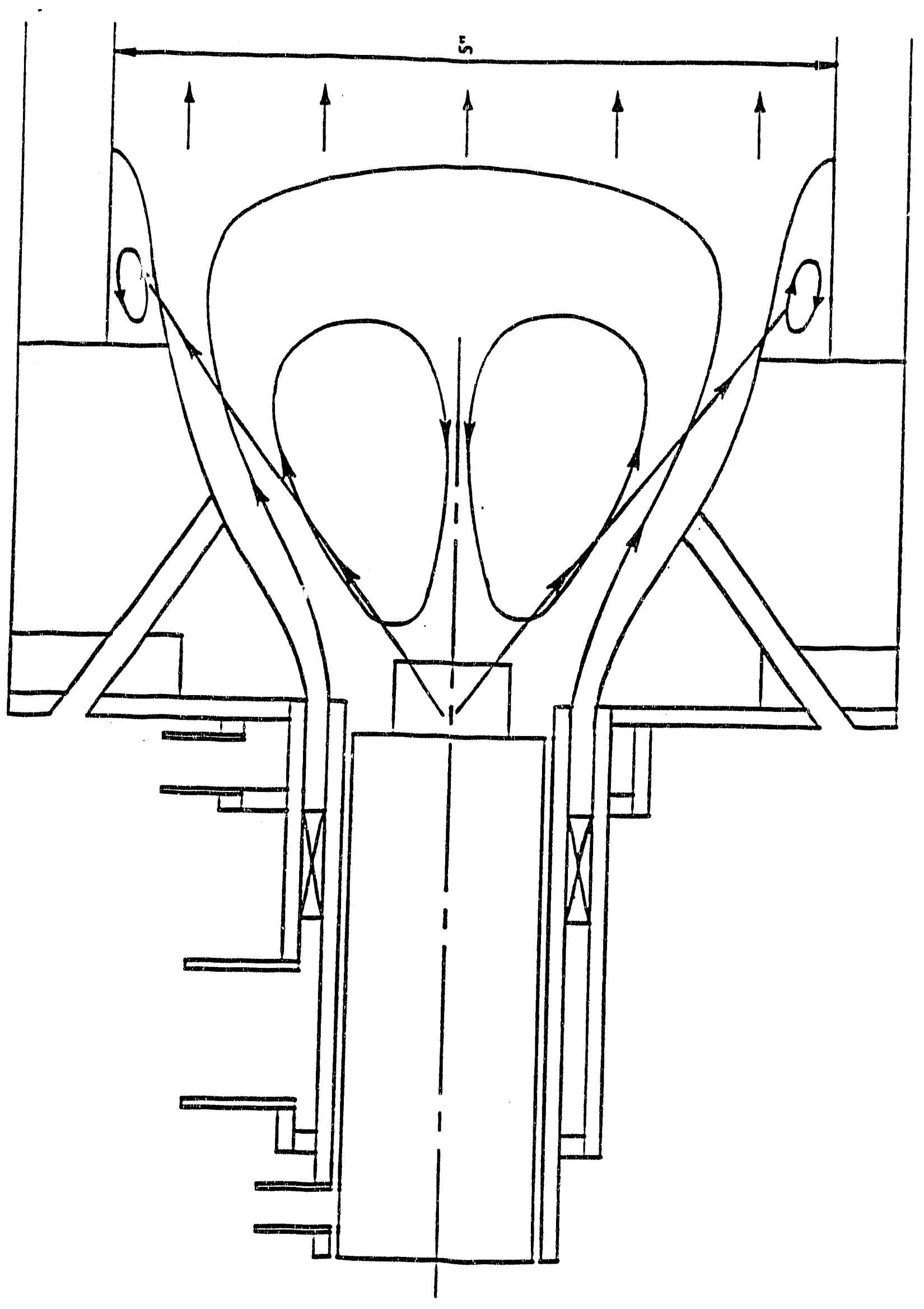


A Parker Hannifin air atomizer designed for CWS will be used to atomize slurry (Figure 4). Two designs of the nozzle are being obtained, a conventional design and a reduced air flow design. The reduced air design uses about. $25 \mathrm{lb} / \mathrm{hr}$ air which corresponds to a air/cWs rate of about $20 \%$.

A list of flow, temperature, pressure and sampling instrumentation which has been installed on the combustor is given below:

- CWS mass flow rate and pressure

- Natural gas flow rate and pressure

- Atomizing air and pressure

- Staging air flow rate and pressure

- Combustor temperatures

- Combustor pressure

- Cooling water flow rate and exit temperature

- Combustor exit gas composition $\left(\mathrm{O}_{2}, \mathrm{CO}_{2}, \mathrm{CO}, \mathrm{NO}_{\mathrm{x}}, \mathrm{SO}_{2}\right)$

The flow rates and pressures will be controlled using a process control and monitoring program.

\section{APPROACH TO HOT GAS CLEANUP EVALUATION}

Particulate collection for the test facility consists of an electrostatic agglomerator followed by a stairmand type high efficiency mechanical collector.

The electrostatic agglomerator is designed to handle flowrates between $30-80$ acfm at the DCFT conditions of interest. Figure 5 is a schematic of the agglomerator concept. The ESA consists of a charging section and agglomerating section each comprised of 4 grounded electrode tubes. The high voltage sections are located concentrically within these tubes. A pulsed energization system will be used to energize the agglomerator. The agglomerating sections will have smooth hollow tubes as high voltage electrodes for providing uniform fields while the charging sections will have controlled curvature on the discharge electrodes for the provision of corona current. Flow can be controlled through any of the tubes 


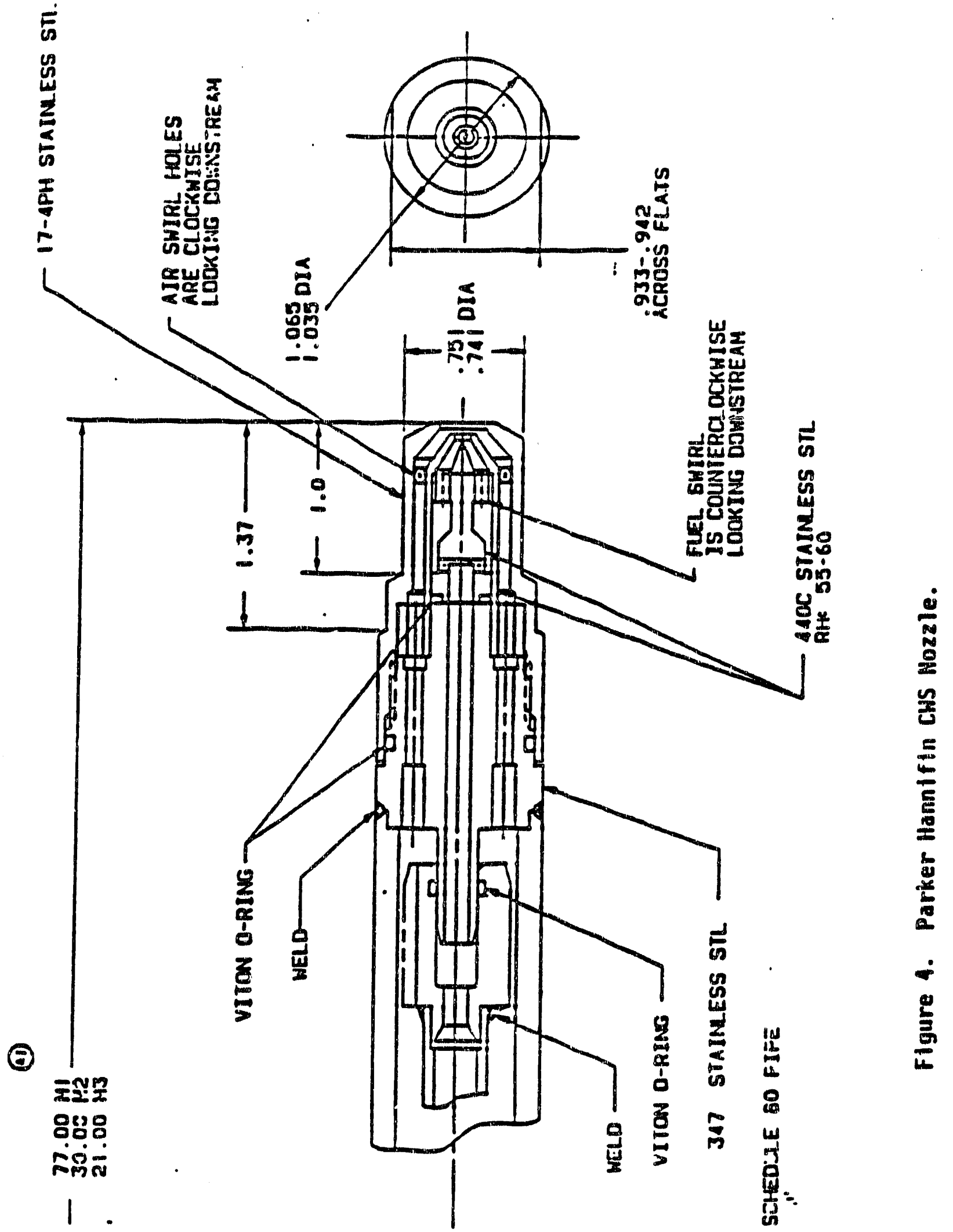




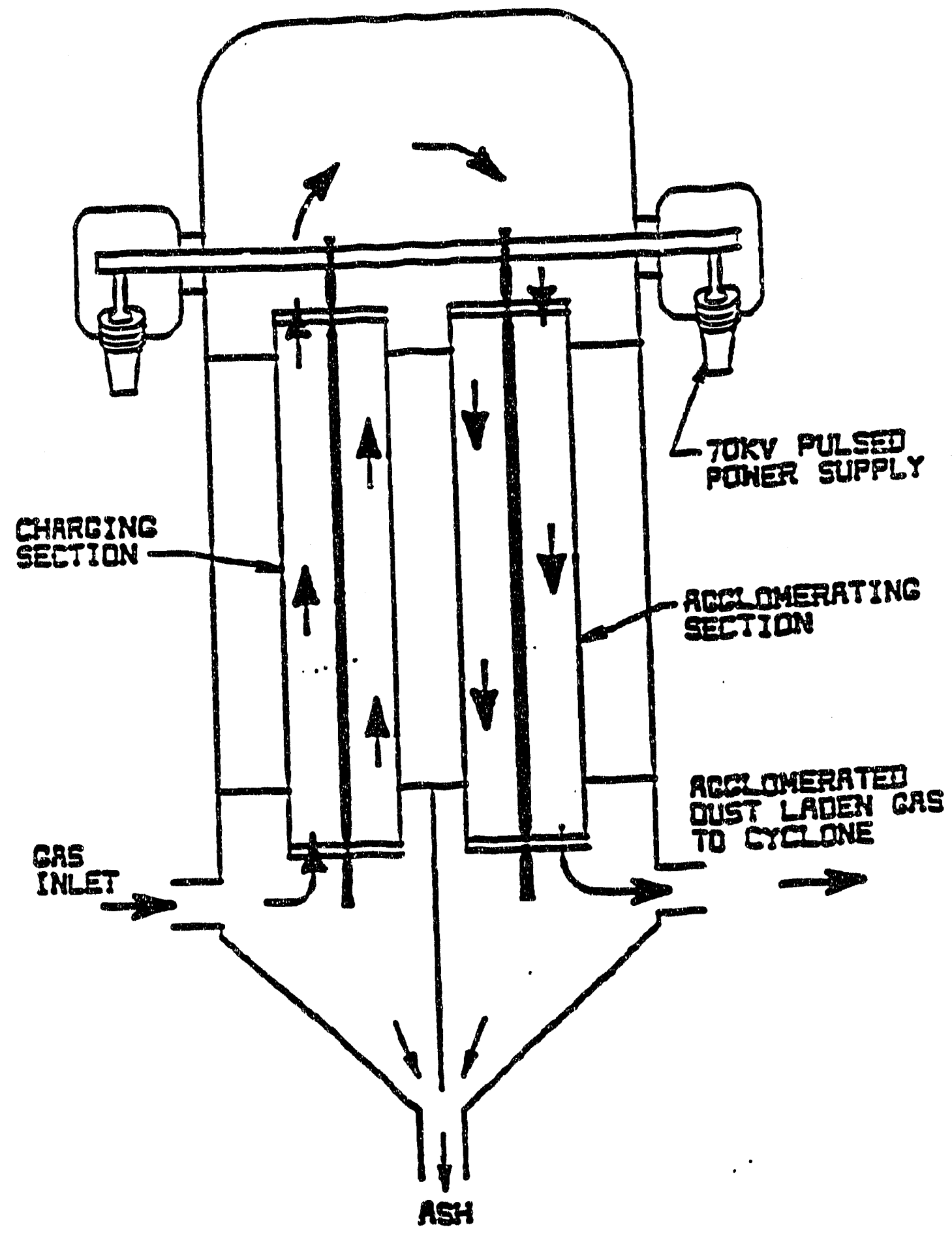

Figure 5 Schematic of Electrostatic Aggiomerator 
in each section. Residence time through ESA can thus be controlled between 0.5 to 3 seconds by a combination of flowrate and number of tubes.

The electrostatic agglomerator performance will depend on the nature of ash and its agglomerative behavior in addition to the parameters such as residence time, applied electric field strengths and the operating temperatures. Therefore the test program should include as variables temperature, gas velocity, residence time and the applied electrical pujsed energization levels as variables for a given process cundition. Figure 6 is a schematic of how the agglomerator system components will fit together.

\section{FUEL SPECIFICATIONS}

It is estimated that 50 tons of coal water slurxy will be required for startup, resting, and fnalysis. Slurry will be manufactured and shipped in 55 gallon arums. Two drums per day will be emptied into a slurry supply tank, connected to the combustor. Slurry specifications are as follows:
a) solids content: 65-70\%
b) particle size: $90 \%$ less than $75 \mathrm{\mu m}$
c) ash content: 8-10\%
d) volatile content: $30 \%$
e) neating valve: $9000 \mathrm{Btu} /$ pound
f) ultimate analysis to be provided.

\section{Quariverly Results}

Electrostatic agglomerator performance depends on the nature of ash and the agglomerative behavior of the ash in addition to the parameters such as residence time, applied electric field strergths, and the operating temperatures. mherefore the planned test program included as variables: operating temperature, gas velocity, and the applied electrical pulsed energization levels for a given process condition. Also, process conditions such as coal. type (sulfur content) and sorbent injection levels were planned as 

controllable variables.

The key goal was to identify those parameters that affected the maximum growth of particulate by electrostatic agglomeration. Data collection that was planned included the particulate loading and size distribution at the agglomerator inlet, outlet, and cyclone outlet. Also, to be measured was the sorbent injection rate, $\mathrm{sO}_{2}$ concertrations at the particulate metering locations, and the pressure and temperature at these locations.

Shakedown consisted of first debugging the individual components and support systems for the combustor. The combustor was designed to fire on both natural gas or coal-water-slurry. Natural gas combustion was used to cure the refractor material and provide information on temperature and pressure ranges of the system as well as temperature stability" Combustion coal-waterslurry was essential for providing coal derived fly ash to the ESA. The individual components and systems that supported the combustor and analytical systems are listed below:

- Main air compressor
- $\quad$ natomizing air compressor
- coal water slurry pump
- pressurizing orifice valve
- control valves
- mass flow meters
- - thersure transducers
- - conission gas quench system
- flame out alarm system
- data acquisition hardware and softwaxe

The combustor and agglomerator were checked for leaks. Leaks were stopped up to an operating pressure of 15 atmospheres.

Following checkout of the individual components, control systems, continuous analyzers, and data acquisition system the combustor was fired on natural gas. During start up on natural gas 
the following tasks were completed:

- cure castable refractory

- Develop $\mathrm{O}_{2} / \mathrm{CO}$ curves for natural gas operation to determine safe operating excess aix levels over the load range.

- Determine load/exit temperature curves at 5\%, 25\%, 50\%, and $100 \%$ excess air over the load range.

- Check control software logic for load under natural gas operation.

After successful continuous operation of the combustor fired on natural gas, coal-water-slurry shakedown testing was to be implemented.

During shakedown of the combustor the temperature maximum of the system was limited to $1800^{\circ} \mathrm{F}$ because of the temperature limitation of the itainless steel agglomerator internals (for example baffle, tube-sheet, and collection(grounded) electrodes).

At the time combustor operation was being tested for temperature stability and pressure stability on natural gas, the electrostatic agglomerator was to be tested for electrical stability by plotting current versus voltage ralationships under different temperatures and pressures. Also, che temperuture profile across the agglomerator was to be measured. Successful demonstration of ESA electrical performance was demonstrated in the range of $800^{\circ} \mathrm{F}$ to $1600^{\circ} \mathrm{F}$ and from 1 atmosphere to 15 atmospheres. Under the shakedown test conditions of the agglomerator the corona producing electrodes (concentration section) were inserted in place of the smooth electrodes (agglomerating section). This was done so that particles leaving the concentration section could be sampled for charge-to-mass measurement once coal water slurry combustion was successful.

The intent of the charge-to-mass measurement determination on the particles exiting the concentrator section was to provide further evidence of the electrostatic charging capabilities under high temperature, high pressure conditions. After successful demonstration of electrostatic charging of fly-ash particles using 
the charge-to-mass measurement technique the ESA was to be reassembled as planned; the discharge (finned) electrodes were to be placed in the inlet (concentrating section) of the agglomerator and the non-discharge (smooth) current producing electrodes were to be placed in the outlet (agglomerating section) of the ESA.

Completion of system debugging (shakedown) was planned with the successful operation of the combustor fired on coal-water-slurry and with the $2 S A$ operating with metal internals at a temperature of $1800^{\circ} \mathrm{F}$ at 10 to 15 atmospheres. Measurement of particle concentration and particle size distribution at the inlet, outlet, and outlet cyclone were planned. Also planned was the monitoring of flue gas constituents by continuous monitors $\left(\mathrm{CO}, \mathrm{CO}_{2}, \mathrm{SO}_{2}, \mathrm{O}_{2}\right.$, and $\left.\mathrm{NO}_{\mathrm{x}}\right)$

\section{Unanticipated Problems and Corrective Actions}

Combustor startup and operation with natural gas were successful after minor corrections were implemented.

Combustor startup issues that needed correction are listod as follows:

1. Water jacket to combustor required new plumbing to increase cooling water flow,

2. Air compressor was purchased as a used unit and needed replacement parts,

3. The flame out sensor repeatedly went off. An air filter was placed in line with the air compressor to remove fine oil mist that coated the sensor window,

4. Minor gas leaks in feed line were corrected.

\section{Burner Modifications for Natural Gas}

There were two locations in the burner for natural gas input: 1. an annulus around the CWS atomizer, and 2. radial injection ports downstream of the primary air swirl vanes. Initially, natural gas was plumbed to the radial location, with high pressure 
"core air" plumbed to the annular location to cool and protect the CWS atomizer. However, due to difficulty experienced in lighting off the combustor with gas, the annular location was used for natural gas input.

\section{Coal-Water-Slurry (CWS) Combustion}

During light off with cWS, two problems were identified with this arrangement. First, the atomizer became too hot and caused the atomizer internal parts to become seized together which prevented atomizer cleaning. Second, the CWS was interfering with the UV sensor while gas was introduced at the annulus, causing the combustor to shut down, even when there was a stable gas flame.

Piping for pressurized natural gas was modified to allow gas to be directed to either the annular or radial location. After the combustor had reached operating temperature, gas could be switched from the annular start up location to the radial location. With gas directed to the radial location and core air directed to the annulus, the combustor was operated with CWS until the atomizer became plugged without a loss of UV signal from the gas flame. In addition, after operation with CWS, the nozzle could be completely disassembled and cleaned without seizing up internally.

However, sustained combustion of CWS as not achieved. Different nozzle designs were tried at varied locations using different atomizing (air/slurry) conditions. Several expeximents were successful in igniti:" $J$ the slurry but the flame would be unsteady and eventually burn out after 20 minutes. The orifice of the atomizing nozzle would eventually plug rendering the system ineffective in achieving a steady temperature.

\section{Fly-Ash Slurry to Replace CWS}

It was decided to abandon CWS combustion as a means to introduce ash to the electrostatic agglomerator. A fly-ash-slurry mixture was thought to be an effective means of introducing fly ash 
into the agglomerator without having to sustain combustion of CWS. Also, since $f l y$ ash has smaller diameter particles as compared to pulverizad coal the plugging problems of atomizing nozzles could be alleviated. A 20\% ash-slurry mixture with water would yield the same grain loadings as attempted with CWS combustion. Coal derived fly-ash was obtained from Nevada Electric's electrostatic precipitator hopper. Nevada Electric burns pulverized coal.

Attempts to atomize $20 \%$ ash-slurry mixture in the combustor while firing $1.5 \mathrm{mBtu} / \mathrm{hr}$ on natural gas were successful. Flame out problems were corrected and no plugging problems were encountered. However, the temperature of the combustor (Ca $2700^{\circ} \mathrm{F}$ ) melted the fly-ash and the combustor acted as a slagging combustor. The efficiency of ash collection on a weight by difference calculation (input ash versus ash collected in the slag pit) was nearly $100 \%$. Sampling of the agglomerator inlet yielded $97 \%$ and $95 \%$ ash collection efficiency in the combustor. The remaining fly ash entering the agglomerator was too low in concentration to be of any use.

The burner was modified by replacing the blind flange, directly opposite to the agglomerator inlet, with a nozzle that could inject ash slurry. In this arrangement the slurxy spray could be directed to the 2" ID inlet section of the agglomerator. By using the nozzle opposite to the inlet of the transport duct $50 \%$ of the ash was transported to the inlet connection of the agglomerator at $1680^{\circ} \mathrm{F}$. However, agglomerator inlet temperatures of $1680^{\circ} \mathrm{F}$ were not sufficient to heat the agglomerator internals above $1350^{\circ} \mathrm{F}$. When the inlet temperature was increased to $2100^{\circ} \mathrm{F}$ the ash melted and impacted on the walls of the inlet duct.

It was then discovered that some shakedown runs performed on coal water slurry combustion trials had temperature overruns because the mass flow controllers of combustion air and natural gas were out of calibration by as much as a factor of 2 . Actual temperature measurements at the agglomerator were not recorded. The bottom flange of the agglomerator was disassembled to inspect the agglomerator stainless steel internals. It was discovered that 
the stainless steel baffle was destroyed by the excessive temperatures. Also, the inlet collection electrodes were warped which prevented the insertion of the corona generating electrodes as prescribed in the original agglomerator design.

The damaged stainless steel baffle was removed and a ceramic (silicon carbide) baffle was installed. Replacement of collection electrodes as well as the labor involved for installation were considered too costly to be implemented. The decision was made to leave the agglomerator corona producing electrodes in the gas exit side of the agglomerator. The damaged inlet tube sheet and stainless steel collection electrodes were left intact.

Use of a fly ash slurry (fly ash from Nevada Power) was not possible at an agglomerator inlet temperature above $1800^{\circ} \mathrm{F}$. The suspended fly ash particles were liquid and were captured by the transport duct leading to the agglomerator inlet. Disassembly of the agglomerator bottom flange revealed that the agglomerator inlet (2" ID) was acting as a glass blowing tube. A brown-green molten bulb of glass was attached to the agglomerator refractory at the inlet.

Injection of a fly ash slurry mixture proved to require more shakedown time than was available in the budget. A slurry of alumina in water was prepared to replace the fly ash slurry. Alumina has a melting point above $3000^{\circ} \mathrm{F}$ so the problem of ash melting was overcome.

As a consequence to the irreparable damage to the grounded electrodes and tube sheet of the inlet (concentrator) section the ESA configuration was no different than a tube type electrostatic precipitator. The concept of electrostatic agglomeration could not be tested within the budget appropriation. However, the testing of the tube type ESP system at temperatures of $1800^{\circ} \mathrm{F}$ and pressures up to 15 atmospheres was considered worthwhile.

A one week particle sampling shakedown plan was designed to examine the following variables affect on alumina collection efficiency:

1. gas velocity. 
2. Particle inlet concentration.

3. ESP power on at $30 \mathrm{KV}$ and power off.

Also, to be examined in the week long test period was the particle size distribution of the inlet and outlet and the particle charge-to-mass ratio at the outlet of the ESP. A Faraday cage type sampling device was designed and fabricated by Dr. Duane Pontius of SRI, International, Birmingham, Alabama for the purpose of obtaining charge-to-mass ratio data.

\section{Atomizer Performance}

Five atomizers were tested during the commissioning of the facility on CWS. The first nozzles tested were the two ParkerHannifin atomizers. Both the normal and reduced air capacity designs were tested. Both atomizers became quickly plugged wi.th CWS at the 0.05 inch orifices located inside the nozzle. Upon recommendation of the manufacturer, the cWs orifices were enlarged to 0.063 inches. This modification resulted in a significantly longer operating period on CWS without clogging. The CWS was injected for as long as an hour before the atomizer clogged. However, while slurry was injected at rates ranging fxom 0.4 to 2.0 $1 \mathrm{~b} / \mathrm{m}$, the flue gas instrumentation indicated that very little of the CWS was actually burning, i.e. only a small decrease in $\mathrm{O}_{2}$ and slight increase in $\mathrm{SO}_{2}$ was observed. After the atomizer became blocked, the furnace was depressurized and the ashpit was found to be full of moist slurry. Additionally, a large amount of coke was found deposited on the furnace refractory walls, indicating impingement of the slurry on the walls.

The Y-jet atomizers were then tested on the combustor. Impingement of the CWS on the refractory wall still occurred, even with the $15^{\circ}$ angle $\mathrm{Y}$-jet nozzle. Additionally, the slurry flow tended to be somewhat erratic indicating plugging of the passages in the $Y$-jet atomizers was also occurring. The slurry was injected for about 2.0 minutes after which time the slurry injection was stopped and the furnace was depressurized. Again, the ashpit was 
found to contain moist slurry and coke was deposited on the furnace walls.

Another attempt was made to burn the CwS by further increasing the slurry holes in the Parker-Hannifin nozzle from 0.063 " to $0.078 "$.

When the combustor was fired using the modified Parker-Hannifin nozzle, a stable slurry flame was established for a period of approximately 30 minutes. A visible coal flame could be seen :hrough the combustor sight glass and through the UV detector port. In time, the top portion of the combustor cooled and the flame became more diffuse, and after 20 minutes, the atomizer became blocked.

During the period the CWS was burning, the gaseous emissions remained relatively steady at $3 \%$ to $4 \% \mathrm{O}_{2}$ and $13 \%$ to $14 \% \mathrm{CO}_{2}$, indicating that near complete burnout was achieved. These tests were conducted at a combustor pressure of 180 psia.

At the conclusion of the test, the combustor was examined. Considerable slag and coke was found along the combustor walls and the ashpit still contained wet, unburned slurry. These observations indicate that although the slurry was burning, a fraction of the slurry still impinged on the reactor walls.

Because of the project time and budget constraints, a decision was made to inject an ash slurry into the combustor while burning gas rather than continue improving the combustor performance on CWS. It was believed that very steady cWS combustion over at least an eight hour time period would be required to obtain acceptable agglomerator operating data. Based on the experience with firing CWS in the 5 inch combustor, the consensus was that achieving the required stability with CWS would demand more time than remained on the project.

The method chosen to generate the ash laden flue gas stream required to assess the agglomerator performance was injection of flyash into natural gas flue gases. A single hole $Y$-jet atomizer was used to inject an ash/watex slurry along the axis of the combustor. Experiments were conducted injecting a $20 \%$ bituminous 
coal slurry into the burner. The slurry was injected without problems for long periods of time (greater than 8 hours). However, measurements showed that the majority of the ash slagged on the refractory walls and was effectively remove from the flue gas stream.

Particulate Samples No. 1, 3 and 4 (Table I) were taken at the ESP inlet when the ash/water slurry was injected at the burner. When the ash was injected at the burner, an average of $97 \%$ of the injected ash did not reach the agglomerator inlet. Examination of the combustor, after injecting ash at the burner top, showed a heavy slag layer coating the furnace walls.

In order to inject the ash at lower temperatures, the slurry atomizer was moved to the clean-out port located directly opposite the horizontal duct leading into the ESA. Particulate samples 2, 5 and 6 (rable I) were taken when the slurry was injected directly into the horizontal duct.

When the ash was injected directly into the horizontal duct leading into the ESP, a major fraction of the ash still formed slag on the walls unless the combustor load was reduced to lower the temperature. At reduced load, $40 \%$ of the injected ash was measured at the agglomerator inlet.

In order to operate the combustor at high temperatures while maintaining an acceptable ash loading into the ESP, a decision was made to use an $\mathrm{Al}(\mathrm{OH})_{3} /$ water slurxy rather than a coal ash slurry. The $\mathrm{Al}(\mathrm{OH})_{3}$ slurry was injected at the side port using the single hole $\mathrm{y}$-jet atomizer. Assuming the aluminum hydroxide completely decomposes to $\mathrm{Al}_{2} \mathrm{O}_{3}$, i.e. $2\left(\mathrm{Al}(\mathrm{OH})_{3}\right) \rightarrow \mathrm{Al}_{2} \mathrm{O}_{3}+3 \mathrm{H}_{2} \mathrm{O}$, approximately $80 \%$ of the injected solid was recovered at the agglomerator inlet.

\section{ESA Operation with Particulate Matter}

Sampling of particulate matter was conducted with a ceramic thimble as part of the ASME Method 17 filter train. Samples were collected before and after the ESA within 15 minutes of each other. simultaneous sampling was not considered necessary since large 
differences in capture efficiency with the electrostatic power on and power off were expected. All sampling was performed at isokinetic rates at a single point location in the $2 "$ ID duct for 10 minutes.

The configuration of the agglomerator was that of an electrostatic precipitator. Therefore, the objective of sampling was to determine the capture efficiency across the agglomerator with the electrostatic power on and with the power off. The electrostatic DC power was set to $30 \mathrm{kV}$ DC. Pulsed energization was not performed. The effects of ash loading, gas velocity, and electrostatic power on particle capture efficiency were tested. Also, attempts were made to test the particulate inlet and outlet size distribution as well r.s the charge-to-mass ratio of the particles exiting the agglomerator.

A chronological summary of all sampling data separated by major events is contained in Table $I$. Sample runs 1-6 utilized a slurry of $20 \%$ fly ash injected in the direction of gas flow (straight run) to the agglomerator. The lower ash slurry feed rates yielded a greater inlet particle loading to the agglomerator. Particle losses in the slurry injection system were greater with increased feed loadings. Also, inlet temperatures greater than $1800^{\circ} \mathrm{F}$ yielded molten ash particles that were removed by the duct between the burner and agglomerator.

Sample runs 7-11 were performed using a 10\% alumina slurxy in place of fly ash. Measurements for runs 7-11 were taken at the inlet of the agglomerator. An alumina slurry (10\%) feed rate of $0.081 \mathrm{~b} / \mathrm{min}$ with $200 \mathrm{scfm}$ flue gas flow proved to provide an adequate particle concentration in the range of 0.93 to 1.5 grains/dscf.

Sample numbers 12-15 were collected at the agglomerator exit using $10 \%$ aiumina slurry. Sample \#13 developed a leak therefore the test results are void. Sample numbers 16-40 represent data collected in the shakedown of the electrostatic precipitator while collecting alumina dust. 
A summery of sample runs $16-40$ is included as Table II. Two flow rates: a) 76 acfm and b) 114 acfm were used with the precipitator activated at $30 \mathrm{KV}$ and also with the precinitator off. Ash loadings at the inlet ranged from 4.66 grains/dscf to 0.95 grains/dscf with all other conditions equal, at a charging voltage of $30 \mathrm{KV}$. The precipitator yielded a capture efficiency of $96.7 \%$ at $30 \mathrm{KV}$ at a velocity of $4.9 \mathrm{ft} / \mathrm{s}$. Physical parameters of the precipitator are listed as Table III.

A cascade impactor sample of the alumina at the precipitator inlet is included in Table IV. The MMD of the alumina was $2.9 \mu \mathrm{m}$ with a GSD of 2.9. One attempt was made to collect the outlet size distribution but the impactor did not pass a post sampling leak test. The pressurizing orifice valve had become eroded from the hot abrasive alumina particles. The damage to the orifice prevented additional data collection.

T'wo attempts were made to determine the particulate charge-tomass ratio at the exit of the discharge section. Only one sample had meaningful results. Problems with the other sample were encountered from the current instability of the measurement device under the high temperature and pressure conditions. The coulomb measurement meter deflected off scale $(t)$ midway through the sample event. The charge-to-mass ratio for the single valid run was on the order of $9 \mu \mathrm{c} / \mathrm{g}$. Additional data collection attempts became impossible when the systems' pressurizing orifice valve eroded from the hot alumina as mentioned above.

\section{Discussion and Conclusions}

Attempts to validate the concept of electrostatic agglomeration were not possible in the shakedown program before budget constraints halted the program. What was learned was that electrostatic precipitation is feasible in the temperature range of $1600-1800^{\circ} \mathrm{F}$ and at pressures above 10 atmospheres. Thus particulate control from pressurized fluid bed combustors may be accomplished with an ESP. The nature of the ash physicochemical properties, such as melting point and ash adhesive force are 
important to the successful demonstration of electrostatic agglomeration. perhaps ash adhesion is even more important to agglomeration as compared to precipitation because ash adhesion is critical for success. Liquid ash particles will present a problem for electrostatic devices as well as barrier filters but sonic jleaning of an electrostatic device may be successful.

In order to demonstrate electrostatic agglomeration there needs to be developed a successful interface between the pressurized coal combustor and hot gas cleanup device. This project ran out of financing before a combustor was developed that could deliver fly ash to the hot gas cleanup device. Designing an electrostatic cleanup device to fit a bench scale combustor that has previously been field demonstrated will offer a greater chance for success.

Collection of the alumina particles under ESP conditions was expected to be on the order of $99 \%$ but the resistivity of alumina was on the order of $10^{5} \mathrm{ohm}-\mathrm{cm}$. Conductive particles are difficult to capture by an ESP. Also, the flow profile through the 4 collection electrodes was unknown. Uneven flow distribution through the gas passage will scour particles from the collection surface. Another variable that would work against efficient capture is ash adhesive properties. Alumina particles had poor adhesive characteristics at $1700^{\circ} \mathrm{F}$. Particles were charged sufficiently $(9 \mu \mathrm{c} / \mathrm{g})$ as determined by the charge-to-mass measurement but did not stick together.

An increase in gas velocity reduces particle collection efficiency in an ESP and this relationship was observed in this program. Also, the precipitator had greater particle emissions with greater inlet ash loadings, from 1 to 4 grains/dscf and this was expected.

It is evident from the work conducted in this program that further research is needed for electrostatic applications in hot gas clean up technologies. Given the limitations of the systems shortcomings that the project was reduced to, there was successful demonstration of effective particle charging at $1700^{\circ} \mathrm{F}$ and 11 atmospheres. Also, the electrostatic system showed that higher 
temperature and pressure applications were feasible (neglecting material Iimitations).

\section{Recommendations for Future Designs}

The major problem experienced during the execution of the test program was in achieving stable operation on coal water slurry. Two separate problems were encountered which prevented successful combustion of the slurry; atomizer :-lugging and impingement of the slurry on the combustor walls. Both the atomizer plugging and spray impingement problems can be primarily attributed to the relatively small scale of the facility.

Although, during the atomizer testing, considerable progress was made in reducing the frequency of atomizer plugging with CWs, the longest run with CWS was approximately one hour. Using a finer grind slurry with the modified Parker-Hannifin nozzle may result in an acceptable performance.

A more difficult problem with the slurry atomization is the impingement of the slurry on the 5 inch internal diameter combustor. The best solution to both the atomizer plugging and spray impingement problems would be to use pulverized coal rather than a slurry for small scale pressurized coal combustor designs. The use of pulverized coal eliminates the atomizer completely and also eliminates the possibility of wet slurry building up in the combustor.

Another consideration for future ESA testing is the difficulty in preventing the ash from slagging on the combustor and transfer piping and never reaching the ESA particularly at gas temperatures above $2000^{\circ} \mathrm{F}$. Although removing the ash as slag in the combustor is a desirable ceature of a commercial concept, the high levels of ash removal (greater than 95\%) achieved with the current combustor design may create difficulties in assessing the ESA removal efficiency.

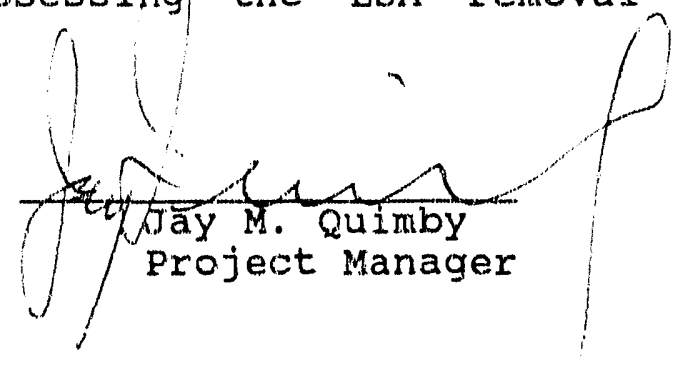




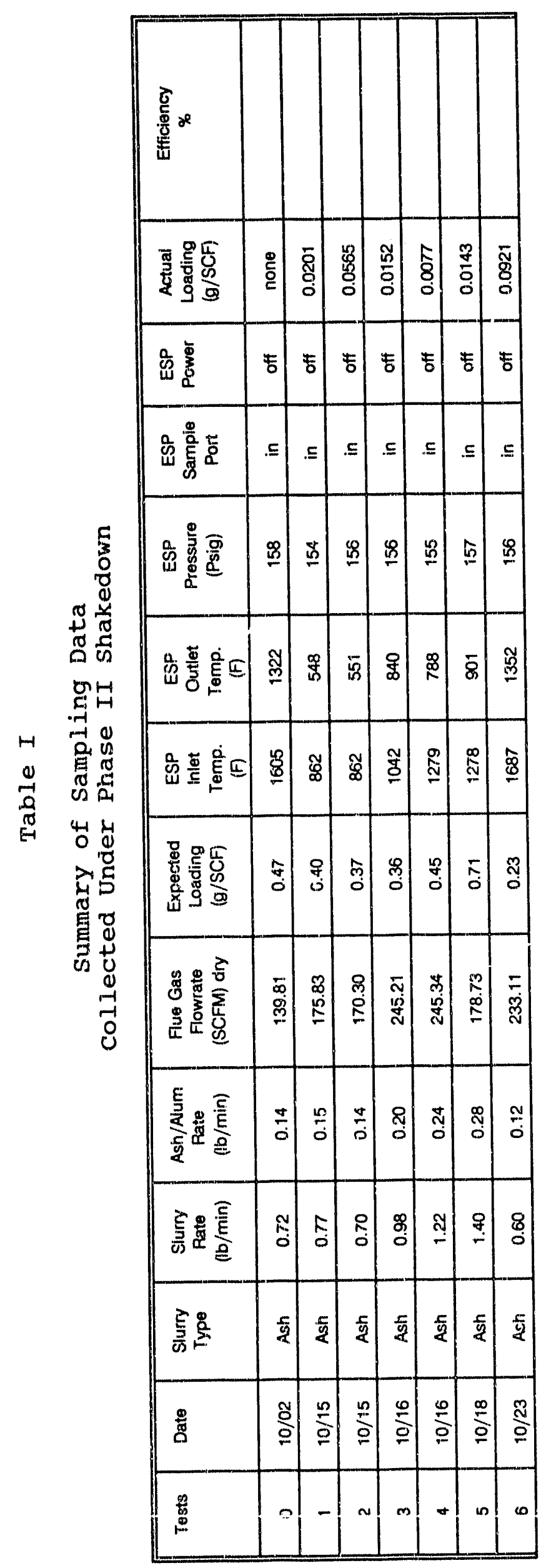




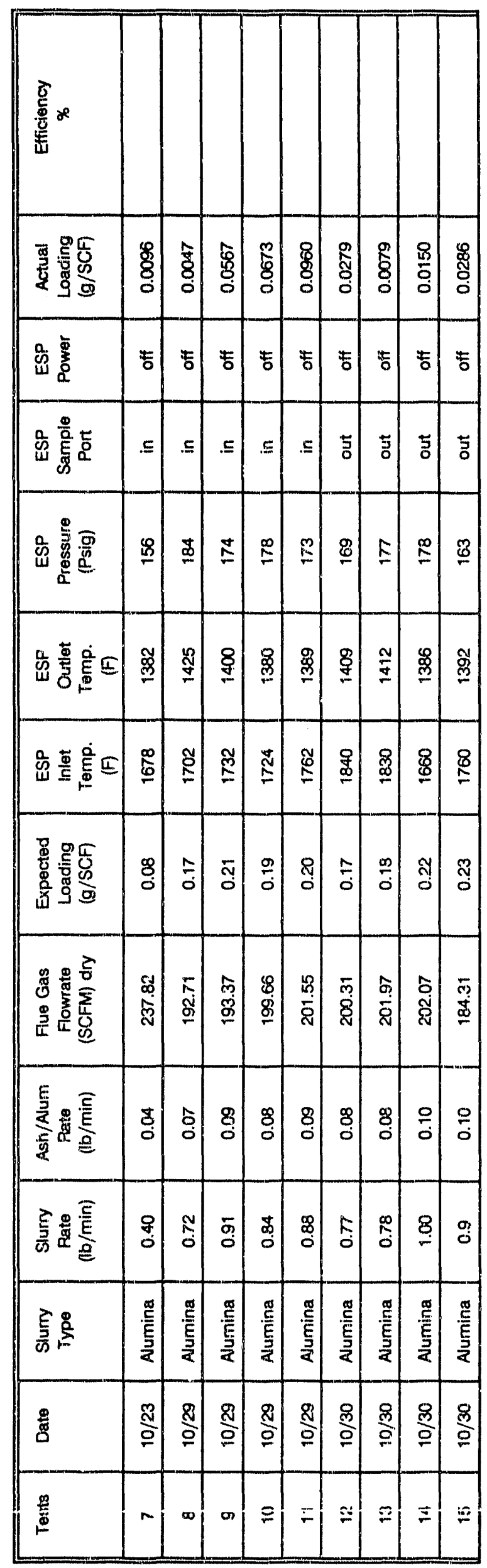




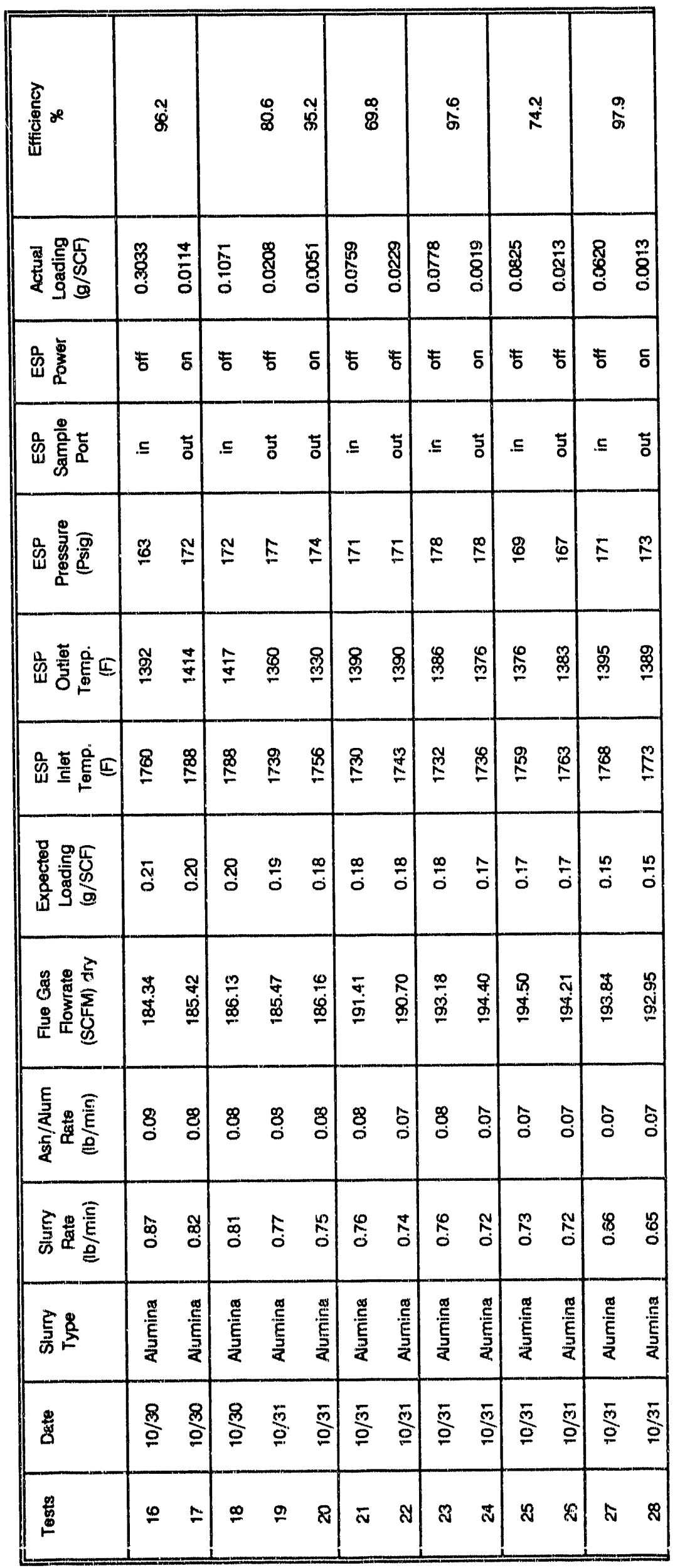




\begin{tabular}{|c|c|c|c|c|c|c|}
\hline 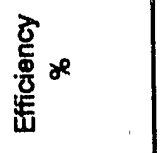 & $\stackrel{3}{0}$ & ูู & $\stackrel{0}{\dot{q}}$ & 亲 & $\stackrel{\infty}{\infty}$ & : \\
\hline 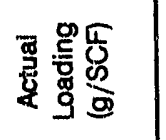 & 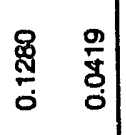 & 喀 & $\begin{array}{cc} & 0 \\
\vdots & 0 \\
0 & 0 \\
0 & 0 \\
0\end{array}$ & 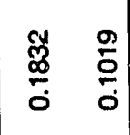 & \begin{tabular}{cc}
$\tilde{N}$ & $\&$ \\
\hdashline & 0 \\
0 & 0 \\
0
\end{tabular} & 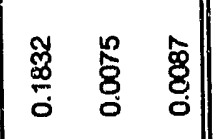 \\
\hline 总高 & 둥 & 告 $\quad$ б & 生 & $\begin{array}{ll}z & \text { t } \\
\end{array}$ & t & 专 5 \\
\hline 递䋜 & $.5 \quad 5$ & $\subseteq 5$ & $\subseteq \quad$ & .5 & $\subseteq 5$ & 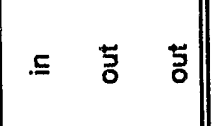 \\
\hline 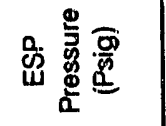 & $\cong ?$ & 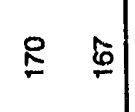 & $\notin 8$ & $\dddot{8}: \mathscr{0}$ & $\begin{array}{ll}8 & 8\end{array}$ & 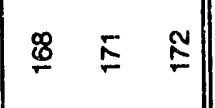 \\
\hline 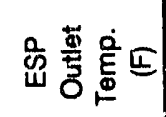 & $\begin{array}{ll}\mathscr{8} \\
\end{array}$ & 昰 & 焉 & 总 & 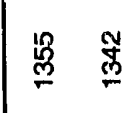 & 总誉亮 \\
\hline 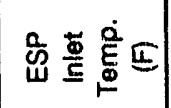 & 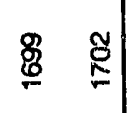 & $\begin{array}{ll} & 0 \\
0 & 0\end{array}$ & $\begin{array}{ll}8 & \overline{8} \\
& \overline{8} \\
\end{array}$ & 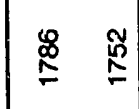 & \begin{tabular}{ll}
$\mathscr{8}$ & 9 \\
\hdashline & 9 \\
\hdashline
\end{tabular} & 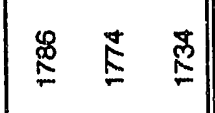 \\
\hline 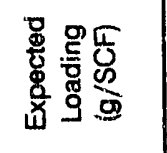 & \begin{tabular}{ll}
8 & 8 \\
\hdashline & 0
\end{tabular} & 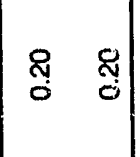 & \begin{tabular}{ll}
9 & ș \\
\hdashline & 0
\end{tabular} & స్త & ָ̃ & 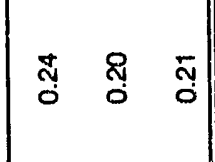 \\
\hline 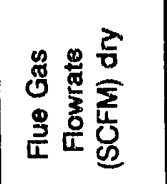 & 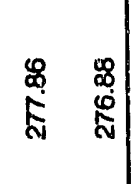 & 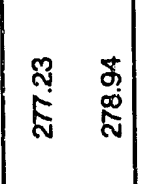 & 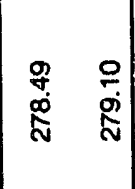 & 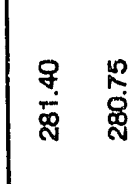 & 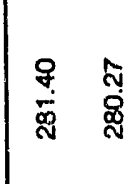 & 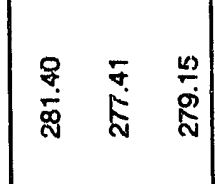 \\
\hline 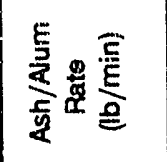 & $\cong \frac{N}{0}$ & $\left|\begin{array}{cc}N & N \\
0 & 0\end{array}\right|$ & $\mid \begin{array}{cc}\cong & 0 \\
0 & 0\end{array}$ & $\frac{m}{0} \frac{m}{0}$ & 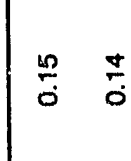 & $\frac{n}{0} \frac{m}{0}$ \\
\hline 㝘器高 & ִָ & דָ & 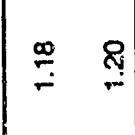 & I & 主 & \& \\
\hline 蛋量 & 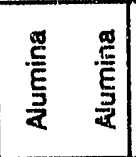 & 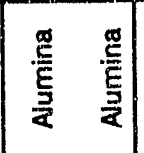 & 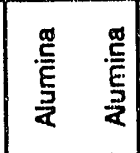 & 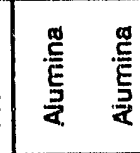 & 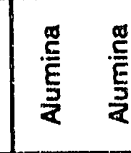 & 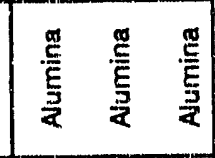 \\
\hline 兽 & 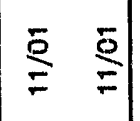 & 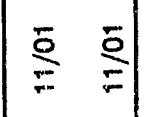 & $\stackrel{\bar{g}}{\bar{g}} \stackrel{\bar{g}}{\overline{2}}$ & $\stackrel{5}{\vdots}$ & $\stackrel{\bar{\Sigma}}{\bar{\Sigma}}$ & $\stackrel{\bar{a}}{\bar{a}} \stackrel{\bar{a}}{=}$ \\
\hline$\frac{9}{6}$ & $8 \quad 8$ & $\bar{n} \quad 0$ & g & 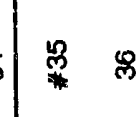 & क & sิ \\
\hline
\end{tabular}


Table II

Summary of ESP Collection Efficiency Shakedown Testing Using Alumina

$\begin{array}{ccccccccc}\text { Date } & \begin{array}{c}\text { Veloci } \\ \text { ty } \\ \text { fps }\end{array} & \begin{array}{c}\text { Inlet } \\ \text { Load } \\ \text { gr/DSCF }\end{array} & \begin{array}{c}\text { Pres } \\ \text { s. } \\ \text { ATM }\end{array} & \begin{array}{c}\text { Inle } \\ t \\ \text { Temp } \\ \text { F }\end{array} & \begin{array}{c}\text { outlet } \\ \text { Temp } \\ F\end{array} & \begin{array}{c}\text { Volt } \\ \text { kV }\end{array} & \begin{array}{c}\text { Captur } \\ \text { e } \\ \text { Effic. }\end{array} & \begin{array}{c}\text { Water } \\ \text { Vapor }\end{array} \\ 10 / 30 / 91 & 4.9 & 4.66 & 11.5 & 1795 & 1418 & 30 & 0.962 & 21 \\ 10 / 31 / 91 & 4.9 & 1.65 & 11.5 & 1795 & 1418 & 0 & 0.806 & 21 \\ 10 / 31 / 91 & 4.9 & 1.65 & 11.5 & 1765 & 1350 & 30 & 0.952 & 21 \\ 10 / 31 / 91 & 4.9 & 1.17 & 11.4 & 1741 & 1400 & 0 & 0.699 & 21 \\ 10 / 31 / 91 & 4.9 & 1.19 & 11.8 & 1740 & 1384 & 30 & 0.975 & 21 \\ 10 / 31 / 91 & 4.9 & 1.27 & 10.9 & 1776 & 1393 & 0 & 0.741 & 21 \\ 10 / 31 / 91 & 4.9 & 0.95 & 11.5 & 1760 & 1391 & 30 & 0.979 & 21 \\ 10 / 31 / 91 & 7.3 & 1.97 & 11.1 & 1707 & 1381 & 0 & 0.672 & 18 \\ 10 / 31 / 91 & 7.3 & 1.54 & 11.1 & 1707 & 1381 & 30 & 0.922 & 18 \\ 11 / 1 / 91 & 7.3 & 1.56 & 11.1 & 1692 & 1351 & 0 & 0.410 & 18 \\ 11 / 1 / 91 & 7.3 & 2.82 & 11.1 & 1773 & 1341 & 30 & 0.888 & 18 \\ 11 / 1 / 91 & 7.3 & 2.82 & 10.9 & 1769 & 1326 & 30 & 0.959 & 18 \\ 11 / 1 / 91 & 7.3 & 2.82 & 10.9 & 1763 & 1372 & 30 & 0.952 & 18\end{array}$




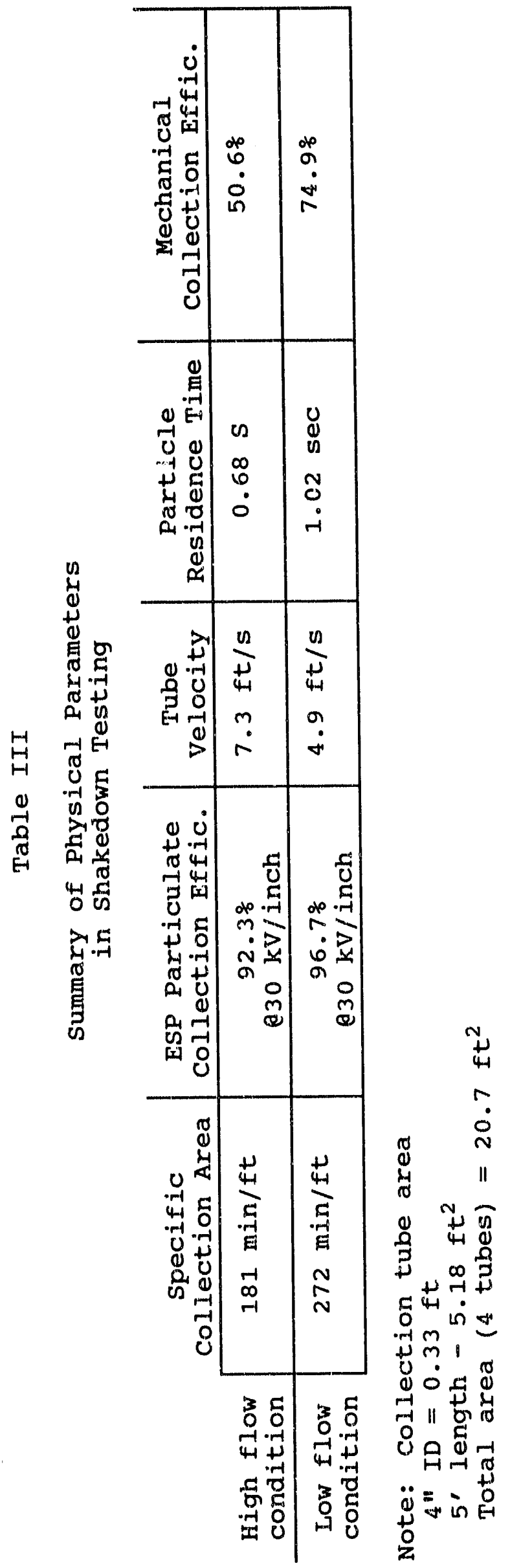


Cascade Impactor Data of ESP Inlet Sampling Alumina Run \#1, Nov 01, 1991

Conditions $350^{\circ} \mathrm{F}$, and $15 \mathrm{~atm}$.

\section{Impactor}

stage

$\begin{array}{cc} & 30.7396 \\ 1 & 21.0894 \\ 2 & 22.0720 \\ 3 & 22.5866 \\ 4 & 15.3450 \\ 5 & 11.1713 \\ 6 & 11.0905 \\ 7 & 11.2119 \\ 8 & 21.6190 \\ \text { Filter } & 0.164\end{array}$

Tare (g) Final (g) Net (g)

31.111
21.4863
22.3042
22.8277
15.4600
11.2213
11.1007
11.2150
21.6214
0.4796

$$
0.018
$$

0.3969

0.2322

0.2411

0.1150

0.0500

0.0102

0.0031

0.0024

0.3161

1.3670
8

$q$ in size cumulative Less Than Range Size Range

29.034

16.986

17.637

8.413

3.658

0.746

0.227

0.176

23.124

70.966

53.980

36.342

27.930

24.272

23.526

23.299

23.124

0.000
Effecti ve Diamete $r$

5.0

3.1

2.1

1.5

0.9

0.5

0.31

0.21 

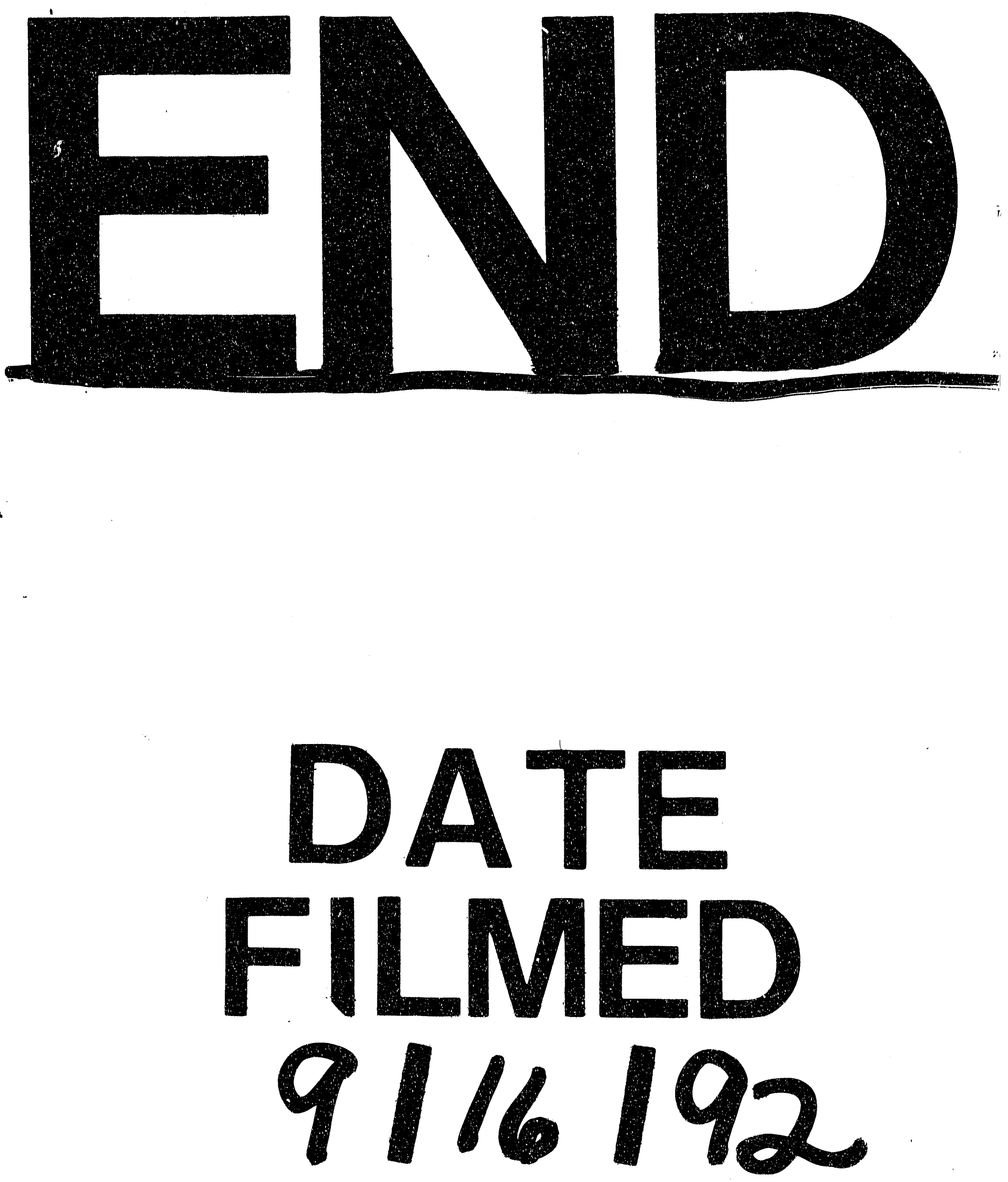
